\title{
Assessment of nasal and oral flow of amniotic fluid in 46 non-anomalous fetuses with sonographic and echocardiographic examination
}

\author{
Rafał Zieliński ${ }^{1}$, Maria Respondek-Liberska² ${ }^{2}$ Stuart Weiner ${ }^{3}$ \\ ${ }^{1}$ Faculty of Medicine and Medical Sciences, Jan Kochanowski University, Kielce, Poland \\ 2 Department of Diagnostics and Prevention of Congenital Malformations, Chair of Morphology and Embryology, \\ Medical University of Lodz, Polish Mother's Memorial Hospital, Poland \\ ${ }^{3}$ Division of Maternal Fetal Medicine, Department of Obstetrics and Gynecology, Thomas Jefferson University, \\ Philadelphia, Pennsylvania, USA
}

\begin{abstract}
Objectives: The aim of the paper was to assess nasal and oral amniotic fluid flows, with the use of color ultrasound and spectral Doppler, in normal fetuses.

Material and methods: Forty-six fetuses of singleton gestations were studied prospectively. Spectrum imaging and maximal nasal fluid flow velocities were described. Episodes of regurgitation (external flow from the mouth), swallowing (internal flow at the level of oropharynx and then entrance to the esophagus) were evaluated in two groups: Fetuses $<27$ weeks of gestation and 27 weeks of gestation and older. Statistical analysis was done using Fischer exact test and t-test at $p=0.05$. Results: Twenty-one fetuses were $<27$ weeks of gestational age and presented mean maximal both inspiratory and expiratory nasal fluid flow velocities significantly lower than twenty-five fetuses who were $\geq 27$ weeks of gestational age $(p=0.035$ and $p=0.031$ respectively, $t$-test). Episodes of regurgitation were observed more frequently in group of "younger" fetuses ( $p=0.006$, Fischer exact test). There was no statistically significant relationship between irregular nasal flow spectrum by color Doppler and gestational age group ( $p=0.264$, Fischer exact test).

Conclusions: Episodes of regurgitation occurred in normal fetuses $<27^{\text {th }}$ week of gestation. Fast amniotic nasal fluid flows without episodes of regurgitation were observed more frequently in fetuses $\geq 27$ weeks and it could be interpreted as an additional sonographic feature of prenatal maturation.
\end{abstract}

Key words: fetal, sonography, doppler, respiratory, digestive

Ginekologia Polska 2018; 89, 6: 316-320

\section{INTRODUCTION}

Prenatal ultrasound allows fetal assessment from the first trimester of pregnancy. The prenatal diagnostics, both ultrasound and echocardiography allows an early evaluation of structural and functional development and defects as well as other pathologies [1-3].

An important indicator of fetal well-being is amniotic fluid volume assessed during the sonographic examination [4], expressed by amniotic fluid index (AFI) [5].The most important mechanism of amniotic fluid resorption is its swallowing by the fetus [6].

Breathing movements resulting in fluid flow in the upper respiratory tract are observed in fetuses and may indicate proper growth and maturing of the respiratory system [7].

Prenatal assessment of fetal head and neck by ultrasound has mainly focused on the visualization of anatomical structures [2]; however observation of fetal behavior, i.e., nasal and oral fluid flow with the use of color Doppler and 
spectral Doppler may be an additional component of fetus examination as suggested by Kalache [8].

\section{Objectives}

The aim of the current research was to assess qualitative and quantitative nasal and oral fluid flows with the use of color and spectral Doppler ultrasound in two age groups of normal fetuses.

\section{MATERIAL AND METHODS}

The study was conducted with the use of methods approved by the Bioethics Committee of our University. Authors have complied with the World Medical Association Declaration of Helsinki regarding ethical conduct of research involving human subjects. Informed consent was received from all patients in this study.

This was a prospective observational study of a group of singleton fetuses with no anomalies on sonographic and echocardiographic examination. Fetuses with structural defects, a difference in gestational age and biometrical age, abnormal AFI index, multiple pregnancies, and functional anomalies were excluded. The study fetuses were divided into two groups: fetuses $<27$ weeks ( $1^{\text {st }}$ and $2^{\text {nd }}$ trimesters) and equal to and older than 27 weeks ( $3^{\text {rd }}$ trimester), based on the last menstrual period and confirmed by biometry.

The examinations with color and spectral Doppler of nasal and oral flows of amniotic fluid were carried out in the Department of Diagnosis and Prevention of Congenital Malformations as an additional part of the routine ultrasound and echocardiography by the same ultrasonographer on the GE Voluson Expert 730 [9] or Philips HDI 5500 [10] sonographic equipment with maximum angle of analysis of 30 degrees. The qualitative and quantitative analyses were performed offline.

Episodes of fluid flow were assessed during 3-5 minutes observation of the fetus' profile in sagittal scan. Nasal and oral fluid flows were recorded as cine or frozen scans showing the direction of the amniotic fluid flow. Next by using a pulsed Doppler sample gate at the level of middle of nasal cavity maximal velocity was measured in both directions
(Vmax in $\mathrm{cm} / \mathrm{s}$ ). In addition, by color Doppler, episodes of regurgitation (external flow at the mouth level) as well as swallowing (internal flow at the level of oropharynx and then entrance to the esophagus) were registered.

The waveforms in spectral Doppler were analyzed for nasal amniotic fluid flow and described as irregular or regular spectrum (at least three subsequent waveforms similar in duration and amplitude of fluid flow velocity). Episodes of a rapid rate flow like regurgitation, spectrum of nasal amniotic fluid flow, both inspiratory and expiratory Vmax, and gestational age were analyzed. For statistical analysis Fischer exact test and t-test were used at $\mathrm{p}=0.05$.

\section{RESULTS}

The initial group included 63 fetuses from singleton pregnancies, but nasal fluid flows were registered and analyzed in 46 "awaken" fetuses.

The mean age of the pregnant women was 32 years 2 months \pm 5 years (range: $22-44$ years). All women were white-Polish primigravidae with low risk of complications with no medical history, with normal prepregnancy BMI (body mass index: 18.5-24.9), no smoking history and no gestational diabetes or hypertension or any medication.

By ultrasound examination there were 22 (48\%) male fetuses and 24 (52\%) female fetuses, with a mean age of $28 \pm 6$ weeks (range: 12-39 weeks). There were 21 younger fetuses with gestational age less than 27 weeks $\left(1^{\text {st }}, 2^{\text {nd }}\right.$ trimesters) and 25 older fetuses at the $27^{\text {th }}$ week and more ( $3^{\text {rd }}$ trimester). The mean AFI was $12.9 \mathrm{~cm} \pm 1.4 \mathrm{~cm}$ (range 10-16 cm) (Tab. 1).

In all 46 fetuses during an active state (not sleeping) nasal bidirectional fluid flow was observed. In addition in 6 (13\%) of the fetuses regurgitation was also seen. Episodes of regurgitation were registered in fetuses less than 27 weeks (Fig. 1).

There was statistically significant relationship between episodes of fluid regurgitation by color Doppler and gestational age related to $1^{\text {st }}, 2^{\text {nd }}$ (less than 27 weeks old) and $3^{\text {rd }}$ trimesters ( $27^{\text {th }}$ week and more), $p=0.006$, Fischer exact test.

Also episodes of swallowing were observed in small number (7-15\%) of older fetuses ( $27^{\text {th }}$ week and more).

Table 1. Data on 46 normal fetuses

\begin{tabular}{|c|c|c|c|}
\hline Data on mothers & $\begin{array}{l}\text { Mean Gestastional age } \\
\text { (last menstrual period) }\end{array}$ & $\begin{array}{l}\text { Gender } \\
\text { of fetuses }\end{array}$ & AFI \\
\hline $\begin{array}{l}\text { White-Polish } \\
\text { Primigravidae } \\
\text { No medical history } \\
\text { Low risk of complications } \\
\text { Normal prepregnancy BMI } \\
\text { No smoking history } \\
\text { No gestational diabetes or hypertension } \\
\text { Aged: } 32 \text { years } 2 \text { months } \pm 5 \text { years (range: } 22-44 \text { years) }\end{array}$ & $\begin{array}{c}28 \pm 6 \text { weeks } \\
\text { (range: } 12-39 \text { weeks) }\end{array}$ & $\begin{array}{l}\text { 1. } 22(48 \%) \\
\text { + } 24(52 \%)\end{array}$ & $\begin{array}{l}12.9 \mathrm{~cm} \pm 1.4 \mathrm{~cm} \\
\text { (range: } 10-16 \mathrm{~cm} \text { ) }\end{array}$ \\
\hline
\end{tabular}




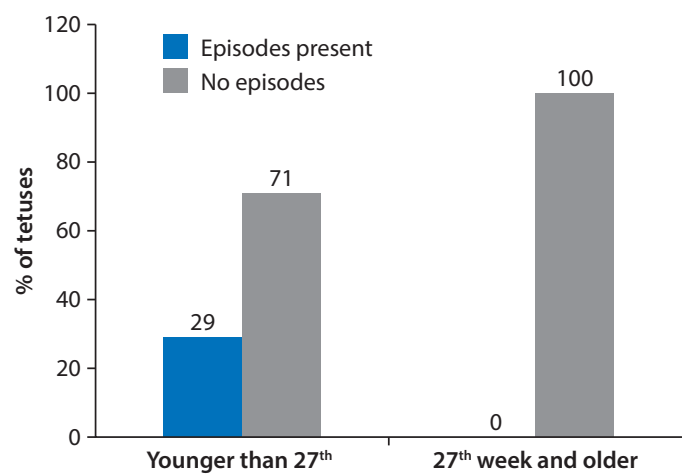

Figure 1. Episodes of regurgitation by Doppler ultrasound in younger fetuses (younger than $27^{\text {th }}$ week) and older fetuses $\left(27^{\text {th }}\right.$ week and older)

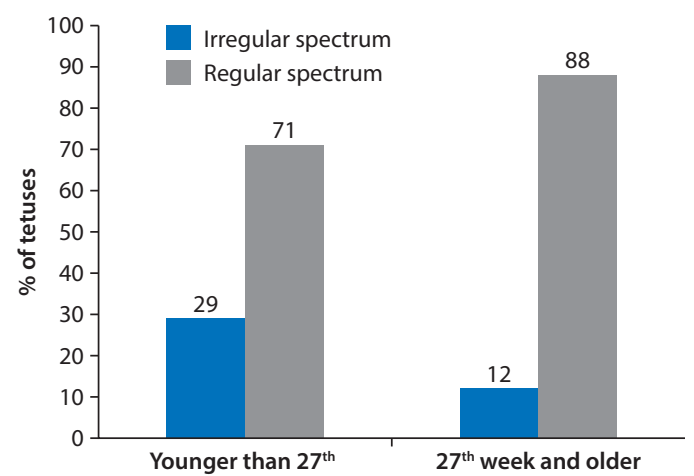

Figure 2. Regular or irregular nasal amniotic fluid flow by spectral pulsed Doppler in younger fetuses (younger than $27^{\text {th }}$ week) and older fetuses ( $27^{\text {th }}$ week and older)

In 37 fetuses (80\%) pulsed Doppler spectrum of nasal amniotic fluid flow was regular whereas in $9(20 \%)$ it was irregular. Irregular spectrum of nasal fluid flow was observed mostly in younger fetuses of less than $27^{\text {th }}$ gestational week (aged: $12,22.5 ; 25 ; 25.6 ; 26.4 ; 26.5$ weeks) and only in 3 older fetuses (30.2, 36.2 and 33 weeks) (Fig. 2).

There was no statistically significant relationship between irregular nasal flow spectrum by color Doppler and gestational age related to $1^{\text {st }}, 2^{\text {nd }}$ (less than 27 weeks old), and $3^{\text {rd }}$ trimesters ( $27^{\text {th }}$ week and more), $p=0.264$, Fischer exact test.

Greater mean maximal velocities of both inspiratory and expiratory nasal amniotic fluid flows were observed in older

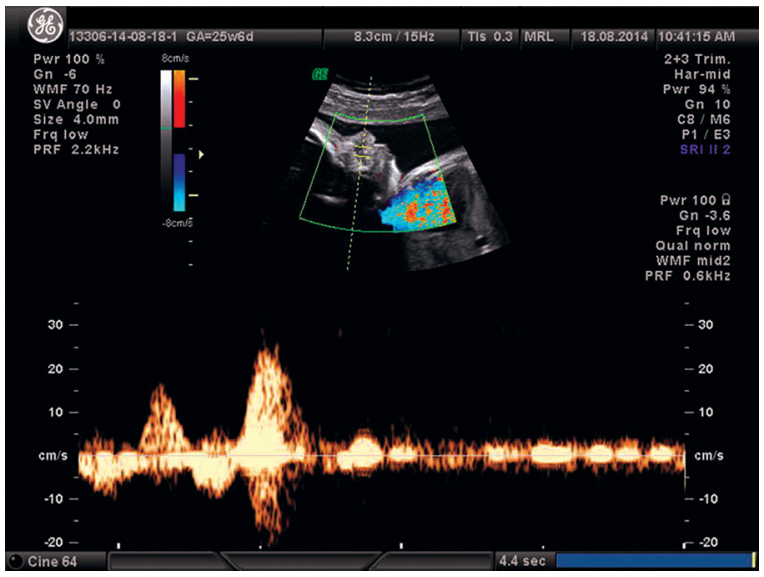

Figure 3. Fetus aged 25.6 weeks. AFI $=15$. Nasal flow by color Doppler and spectral Doppler in the sagittal plane. Irregular bidirectional fluid flow at the nose level, inspiratory $\operatorname{Vmax} 18 \mathrm{~cm} / \mathrm{s}$, expiratory Vmax $25 \mathrm{~cm} / \mathrm{s}$

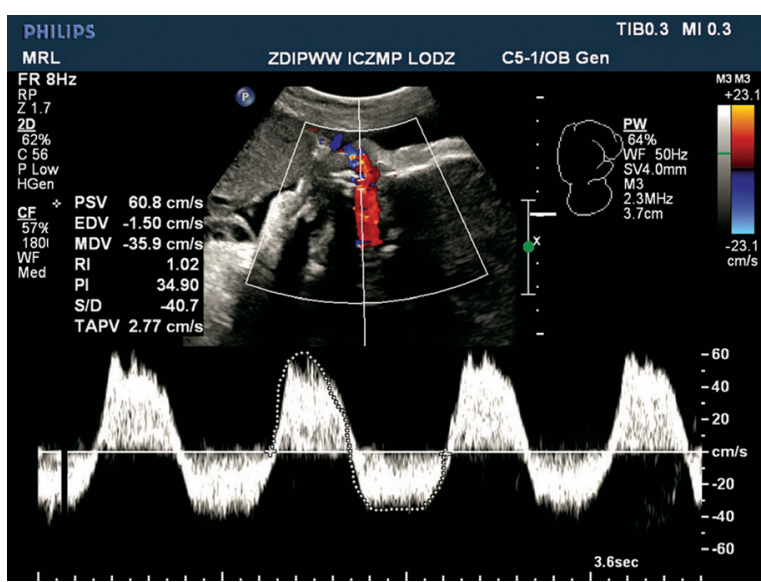

Figure 4. Fetus aged 37 weeks. $A F I=12$. Nasal flow by color Doppler and spectral Doppler in the sagittal plane. Regular bidirectional fluid flow at the nose level, inspiratory $V \max 40 \mathrm{~cm} / \mathrm{s}$, expiratory $V \max 60 \mathrm{~cm} / \mathrm{s}$

fetuses (Fig. 3, Fig. 4). Statistically significant difference in mean maximal inspiratory fluid flow velocities was found in a group of fetuses less than 27 weeks and older. There was also statistically significant difference in the mean expiratory maximal velocities between younger fetuses of less than $27^{\text {th }}$ week of gestational age and older (Tab. 2).

Table 2. Mean maximal nasal amniotic fluid flows' velocities in younger fetuses (younger than $27^{\text {th }}$ week) and older fetuses (27 $7^{\text {th }}$ week and older)

\begin{tabular}{l|c|c|}
\hline & \multicolumn{1}{c|}{ Inspiratory nasal fluid flow } & Expiratory nasal fluid flow \\
\hline $\begin{array}{l}\text { Mean maximal nasal fluid flow velocities in a group of } \\
\text { fetuses younger than } 27^{\text {th }} \text { week (21) }\end{array}$ & $26 \mathrm{~cm} / \mathrm{s} \pm 9.7 \mathrm{~cm} / \mathrm{s}$ (range: $5-40 \mathrm{~cm} / \mathrm{s}$ ) & $26 \mathrm{~cm} / \mathrm{s} \pm 8.5$ (range: $5-40 \mathrm{~cm} / \mathrm{s}$ ) \\
\hline $\begin{array}{l}\text { Mean maximal nasal fluid flow velocities in a group of } \\
\text { fetuses at } 27^{\text {th }} \text { week and older (25) }\end{array}$ & $31.8 \mathrm{~cm} / \mathrm{s} \pm 8.1$ (range: $20-50 \mathrm{~cm} / \mathrm{s}$ ) & $32.4 \mathrm{~cm} / \mathrm{s} \pm 11.2(\mathrm{range:} 15-60 \mathrm{~cm} / \mathrm{s}$ ) \\
\hline $\begin{array}{l}\text { Difference in mean maximal nasal fluid flow velocities } \\
\text { found in a group of fetuses younger than } 27^{\text {th }} \text { week } \\
\text { and fetuses at } 27^{\text {th }} \text { week and older ( } p \text { value, t-test) }\end{array}$ & $\mathrm{p}=0.035$ & $\mathrm{p}=0.031$ \\
\hline
\end{tabular}




\section{DISCUSSION}

The first attempts to assess nasal fluid flow in fetuses by ultrasound date back to the1990s [7]. Cosmi published an observation of fetal breathing movements on a change in the position of the chest and abdomen as well as fluid flow in the nose. However, he did not present qualitative or quantitative assessment of the fetal nasal fluid flow [11, 12].

Prenatal evaluation of the nasal cavity and a part of throat allows good observation of nasal fluid flow and fetal swallowing is optimized in a sagittal cross-section assessment by two-dimensional Doppler ultrasonography [13]. Movements of "colored"fluid against the background of grey anatomical structures enable not only observation of stages of the swallowing reflex but also assessment and recording of physiological activities of fetal upper respiratory and digestive tracts [14].

For better practical evaluation and future application of our results, the study group was divided into younger fetuses (less than 27 weeks old) and older fetuses ( $27^{\text {th }}$ week and more).

Suzuki stressed the importance of nasal fluid flow examination by ultrasonography with spectrum assessment to evaluate fetal respiratory tract functions. The author found that a regular pattern of fetal nasal fluid flow was characteristic in the $3^{\text {rd }}$ trimester of gestation [13]. In our study on normal fetuses by sonographic and echocardiographic examination at the $27^{\text {th }}$ and more weeks of gestation, irregular fluid flow in the upper respiratory and digestive tracts was found very rarely.

The sonographic examination of nasal and oral fluid flows may be hampered by a difficult position of the fetal head. Badalion described patterns of perinasal fluid flow observing inspiration and expiration stages over a long period of time [15]. We assessed nasal and oral fluid flows in a 3-max 5 minute "additional examination" and it was not possible to obtain the data in all 63 fetuses who qualified for the study, but it was possible in 46 "awaken" fetuses (73\%).

Phylogenetically, the swallowing reflex is an old reflex $[6,16]$. At the same time fetal breathing movements, which cause fluid flow in the upper respiratory and digestive tracts and observed already in the $1^{\text {st }}$ trimester suggest that there has been proper growth and maturation of both the lower and upper tracts and their connections with the amniotic fluid cavity. Coordination of these reflexes appears and develops in intrauterine life and depends on appropriate development of anatomical structures of the respiratory and digestive tract structures as well as the nervous system [17]. It may account for more frequent episodes of regurgitation and irregularity of nasal fluid flow spectrum in younger fetuses, as the neural control mechanisms have not yet fully developed.
In our observation nasal amniotic fluid flow was much more frequently observed comparing to the swallowing, which was ascertained only in older fetuses. It may suggest a hypothesis that from ontogenetic point of view human fetus may mature earlier for respiration than for digestion function. The topic warrants further research.

Registering of fluid flow in the upper respiratory tract with use of Doppler ultrasound is easy but its assessment appeared to be difficult. We present an old ultrasound technique to study new aspects of fetal physiology, which might be useful for a better understanding of normal and abnormal fetal behavior. Our studies also confirm the possibility of fetal nasal and oral fluid flow assessment by color and spectral Doppler ultrasound. Perhaps if it were included in the fetus' prenatal "physiological" assessment it would be possible in the future to detect anomalies leading to the congenital central hypoventilation syndrome (CCHS) also referred to as Ondine's syndrome.

The current studied population consisted only of normal fetuses, of mothers who were primigravidae with no medical history and with no medications.

Possibly nasal and oral amniotic fluid assessment by Doppler would be a useful tool in the prenatal neurologic assessment on a longitudinal basis. It should also be verified for fetuses with anomalies.

\section{CONCLUSIONS}

Episodes of regurgitation occured in normal fetuses $<27^{\text {th }}$ week of gestation. Fast amniotic nasal fluid flows without episodes of regurgitation were observed more frequently in fetuses $\geq 27$ weeks and it could be interpreted as an additional sonographic feature of prenatal maturation.

\section{REFERENCES}

1. Zieliński R, Respondek-Liberska M. Craniofacial malformations in prenatal ultrasound evaluation. Literature review. Ginekol Pol. 2013; 84(9): 801-806, doi: 10.17772/gp/1643, indexed in Pubmed: 24191520.

2. Zielinski R, Respondek-Liberska M. Retrospective chart review of 44 fetuses with cervicofacial tumors in the sonographic assessment. Int J Pediatr Otorhinolaryngol. 2015; 79(3): 363-368, doi: 10.1016/j. ijporl.2014.12.027, indexed in Pubmed: 25600283.

3. Sikorski M. Rapidly progressive, large nascent cervical myoma with intrauterine device - case report and review of literature. Medical Studies. 2017; 1: 51-54, doi: 10.5114/ms.2017.66958.

4. Beall MH, van den Wijngaard JP, van Gemert MJC, et al. Amniotic fluid water dynamics. Placenta. 2007; 28(8-9): 816-823, doi: 10.1016/j.placenta.2006.11.009, indexed in Pubmed: 17254633.

5. Panting-Kemp A, Nguyen T, Castro L. Substance abuse and polyhydramnios. Am J Obstet Gynecol. 2002; 187(3): 602-605, doi: 10.1067/mob.2002.124292, indexed in Pubmed: 12237634.

6. Modena AB, Fieni S. Amniotic fluid dynamics. Acta Biomed. 2004; 75 Suppl 1: 11-13, indexed in Pubmed: 15301282.

7. Badalian SS, Chao CR, Fox HE, et al. Fetal breathing-related nasal fluid flow velocity in uncomplicated pregnancies. Am J Obstet Gynecol. 1993; 169(3): 563-567, doi: 10.1016/0002-9378(93)90621-0, indexed in Pubmed: 8372863.

8. Kalache KD, Chaoui R, Bollmann R. Doppler assessment of tracheal and nasal fluid flow during fetal breathing movements: preliminary 
observations. Ultrasound Obstet Gynecol. 1997; 9(4): 257-261, doi: 10.1046/j.1469-0705.1997.09040257.x, indexed in Pubmed: 9168577.

9. GE Healthcare Voluson 730 product site. 2015 [27/11/2015]. http:// www3.gehealthcare.com/en/Products/Categories/Ultrasound/Voluson/Voluson_730.

10. Ultrasound by Philips. 2015. http://www.healthcare.philips. com/main/products/ultrasound/. (27/11/2015).

11. Cosmi EV, Anceschi MM, Cosmi $E$, et al. Ultrasonographic patterns of fetal breathing movements in normal pregnancy. Int J Gynaecol Obstet. 2003; 80(3): 285-290, doi: 10.1016/s0020-7292(02)00384-3, indexed in Pubmed: 12628530.

12. La Torre R, Cosmi E, Anceschi MH, et al. Preliminary report on a new and noninvasive method for the assessment of fetal lung maturity. J Perinat Med. 2003; 31(5): 431-434, doi: 10.1515/JPM.2003.067, indexed in Pubmed: 14601267.

13. Suzuki M, Saito $H$, Yanaihara T. Assessment of fetal nasal fluid flow by two-dimensional color Doppler ultrasonography during pregnancy. J Matern Fetal Med. 1999; 8(4): 159-163, doi: 10.1002/(SICI)1520-66
61(199907/08)8:4<159::AID-MFM4>3.0.CO;2-O, indexed in Pubmed: 10406298.

14. Macedonia C, Miller JL, Sonies BC. Power Doppler imaging of the fetal upper aerodigestive tract using a 4-point standardized evaluation: preliminary report. J Ultrasound Med. 2002; 21(8): 869-878, doi: 10.7863/jum.2002.21.8.869, indexed in Pubmed: 12164572.

15. Badalian SS, Fox HE, Zimmer EZ, et al. Patterns of perinasal fluid flow and contractions of the diaphragm in the human fetus. Ultrasound Obstet Gynecol. 1996; 8(2): 109-113, doi: 10.1046/j.1469-0705.1996.08020109.x, indexed in Pubmed: 8883313.

16. Petrikovsky BM, Kaplan GP, Pestrak H. The application of color Doppler technology to the study of fetal swallowing. Obstet Gynecol. 1995; 86(4 Pt 1): 605-608, doi: 10.1016/s0029-7844(95)80025-5, indexed in Pubmed: 7675388.

17. Levy DS, Zielinsky P, Aramayo AM, et al. Repeatability of the sonographic assessment of fetal sucking and swallowing movements. Ultrasound Obstet Gynecol. 2005; 26(7): 745-749, doi: 10.1002/uog.1868, indexed in Pubmed: 16161177. 